\title{
Design, Synthesis, and Implementation of Sodium Silylsilanolates as Silyl Transfer Reagent
}

\author{
Hiroki Yamagishi, Hayate Saito, Jun Shimokawa, * Hideki Yorimitsu* \\ Department of Chemistry, Graduate School of Science, Kyoto University, Kyoto, 606-8502, Japan.
}

\begin{abstract}
There is an increasing demand for facile delivery of silyl groups onto organic bioactive molecules. One of the common methods of silylation via a transition metal-catalyzed coupling reaction employs hydrosilane, disilane, and silylborane as major silicon sources. However, labile nature of the reagents or harsh reaction conditions sometimes renders them inadequate for the purpose. Thus, a more versatile alternative source of silyl groups has been desired. We hereby report a design, synthesis, and implementation of new storable sodium silylsilanolates that can be used for the silylation of aryl halides and pseudohalides in the presence of a palladium catalyst. The new method allows a late-stage functionalization of polyfunctionalized compounds with a variety of silyl groups. Mechanistic studies indicate that 1) a nucleophilic silanolate attacks a palladium center to afford a silylsilanolate-coordinated arylpalladium intermediate and 2) a polymeric cluster of silanolate species assists in the intramolecular migration of silyl groups, which would promote an efficient transmetalation.
\end{abstract}

\section{Introduction}

Silicon typically adopts four covalent, tetrahedrally disposed bonds in molecular architectures, so that it resembles one of the most fundamental elements of Life, carbon. The major difference between these two group 14 elements lies in electronegativity and in the bond length to the adjacent atoms. Thus, in the realm of silicon-containing drugs and bioactive molecules, ${ }^{[1]}$ a carbon atom could be exchanged to a silicon atom as a bioisostere to modify the physical and biological characters. Through these strategies known as "silicon switch ${ }^{[1]] ", ~ s i l i c o n-c o n t a i n i n g ~ b i o a c t i v e ~}$ molecules have been successfully devised (Figure 1). RXR-selective retinoid antagonist, bexarotene, has been redesigned to disila-bexarotene by exchanging two carbon atoms with silicon atoms without detrimental effect on bioactivity. ${ }^{[2]}$ The silicon switch strategy has also effectively proposed potent sila-analogues of acaricide Cyflumetofen ${ }^{[3]}$ and p38 MAP kinase inhibitor Doramapimod ${ }^{[4]}$ (BIRB 796). As illustrated in these examples, the substitution of tert-butyl group with a bioisosteric trimethylsilyl (TMS) group is an intriguing tactic for changing physico-chemical properties such as human microsomal stability, without lowering the biological activities. 


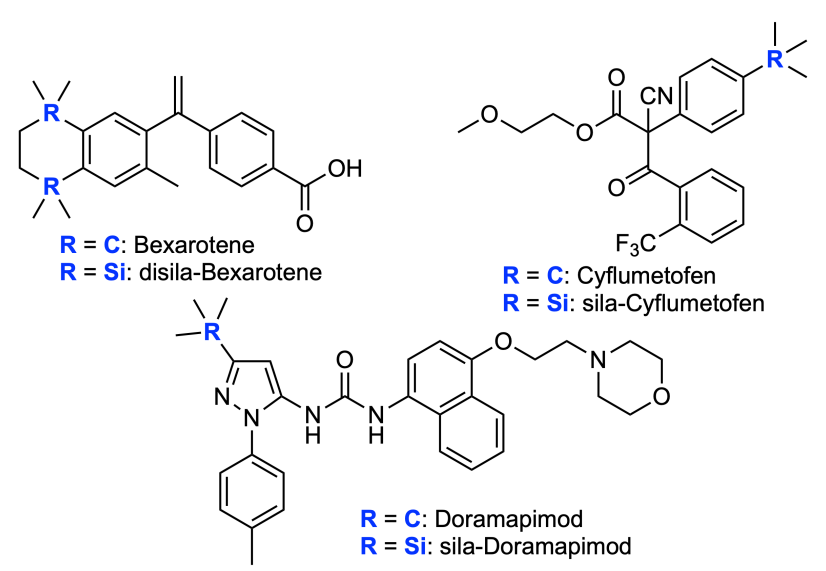

Figure 1. Sila-analogs Developed via Carbon/Silicon Switch Strategy.
A. Silylating Reagents Employed in Transition Metal-catalyzed Silylation of Aryl (pseudo)Halides

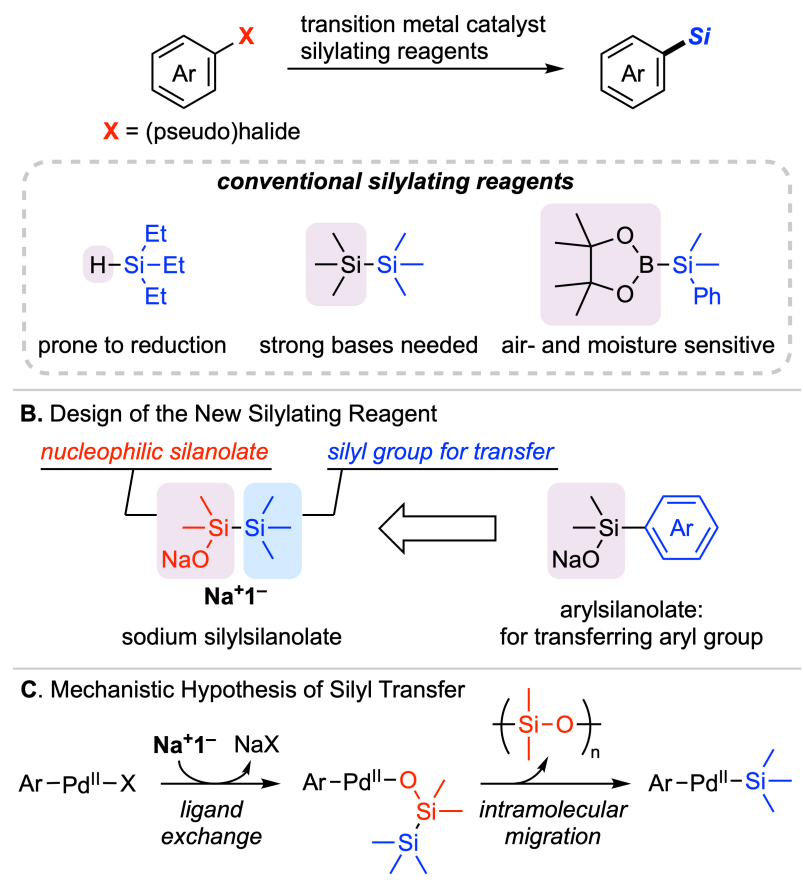

Figure 2. Blueprint for Development of Sodium Silylsilanolate.

Despite these successful implementation of the silicon switch strategy, synthetic approaches to complex silicon-containing molecules have been restricted. We hypothesized that this difficulty would be due to the lack of an appropriate reagent for transition metal-catalyzed silylation of aryl halides, which could also be amenable to the late-stage functionalization of complex molecules (Figure 2A). Commonly used reagents for those silylation can be mainly classified into three silicon species, hydrosilanes, disilanes, and silylboranes. Hydrosilanes often provide reduced products during transition metal-catalyzed silylation reaction, which often complicates the reaction consequences. ${ }^{[5]}$ Particularly, trimethylhydrosilane is a gaseous and pyrophoric reagent that is practically unrealistic to use in the laboratory. Symmetric disilanes are less likely to cause transmetalation, so that relatively high temperature $\left(>100^{\circ} \mathrm{C}\right)$ and strong bases are often necessary for the activation. ${ }^{[6]}$ In most cases, hexamethyldisilane is employed as a reagent, and judicious choice of the ligand is often necessary to each substrate. Thus, the use of disilanes leads to the reduced variation of the silyl groups and functional group tolerance. Silylboranes ${ }^{[7]}$ are relatively new breed of silylation reagents that can be used in transition metal-catalyzed silylation of aryl (pseudo)halides. ${ }^{[7 b, 8]}$ While silylboranes bearing a bulky silyl groups are reported to be stable, ${ }^{[9]}$ typical silylborane $\mathrm{Me}_{2} \mathrm{PhSi}-\mathrm{Bp} i n$ is known to be air- and moisture-sensitive ${ }^{[7 b]}$ and $\mathrm{Me}_{3} \mathrm{Si}-\mathrm{Bp}$ in is inevitably fairly labile so that it is reported to hydrolyze during purification. ${ }^{[10]}$ This labile nature renders silylboranes inappropriate to deliver TMS group. In terms of silylation reaction, the simplest 
trialkylsilyl group, TMS, is definitely no trivial one. By going through these three reagents, it is now evident that the development of a novel practical silylating reagent is necessary for more efficient silylation under mild conditions.

Herein, we propose sodium trimethylsilyldimethylsilanolate $\left(\mathrm{Na}^{+} \mathbf{1}^{-}\right)$as a new silylating reagent that works in the presence of palladium catalyst (Figure 2B). The design of this reagent was inspired by analogy to arylsilanolates that have been known as reagents for transferring aryl groups in palladium-catalyzed cross-coupling reactions. ${ }^{[1]]}$ The molecular structure of $\mathbf{N a}^{+} \mathbf{1}^{-}$contains one $\mathbf{S i}-$ Si bond that connects a TMS group to be delivered and a nucleophilic silanolate as a catapult. We hypothesized the mode of migration of a silyl group from silylsilanolate shown in Figure $2 \mathrm{C}$, based upon a similar system for arylsilanolate proposed by Denmark. ${ }^{[11 \mathrm{~g}]}$ In contrast to the ordinary disilanes, anionic silylsilanolate can act as a nucleophile that attacks the palladium (II) center to form a silylsilanolate-coordinated intermediate. This proximity effect would facilitate an intramolecular delivery of the terminal silyl group to the palladium center, with concomitant formation of a waste polysiloxane.

\section{Results and Discussion}

$\mathrm{Na}^{+} \mathbf{1}^{-}$was easily synthesized from commercially available chloropentamethyldisilane $\mathbf{1}$ over two steps (Scheme 1A): hydrolysis of a chlorosilane in an acetate buffer to afford a silanol and the subsequent deprotonation with $\mathrm{NaH}$. The reagent was obtained as an analytically pure, mildly hygroscopic, and thermally stable white powder that can be easily handled in a dry atmosphere. Sodium silylsilanolates other than $\mathbf{N a}^{+} \mathbf{1}^{-}$were synthesized as shown in Scheme 1B. Commercially available 1,2-dichlorotetramethyldisilane was treated with nucleophilic organometallic species $(\mathrm{BnMgBr}$, tBuLi, allyl $\mathrm{ZnCl})$ to mediate mono-substitutions to give the corresponding chlorodisilanes $\mathbf{2}, \mathbf{3}$, and $\mathbf{4}^{[12]}$. Hydrolysis of 2-4 followed by deprotonation with $\mathrm{NaH}$ provided the corresponding sodium silylsilanolates $\mathrm{Na}^{+} 2^{-}-\mathrm{Na}^{+} 4^{-}$in good yields. $\mathrm{Na}^{+} 2^{-}$and $\mathrm{Na}^{+} 3^{-}$were obtained as white solids, and $\mathbf{N a}^{+} \mathbf{4}^{-}$was isolated as a sticky oil.

In order to evaluate the synthetic utility of sodium silylsilanolate, we studied the silylation of aryl bromide 5 in the presence of a palladium catalyst with $\mathbf{N a}^{+} \mathbf{1}^{-}$(Table 1). Under our optimized standard conditions, treatment of ethyl 4-bromobenzoate (5) with preformed MePhos Pd G4 (3 mol\%), ${ }^{[13]} \mathbf{~ N a}^{+} \mathbf{1}^{-}$(2.0 equiv) in 1,2-dichloroethane (DCE) as the solvent at $50{ }^{\circ} \mathrm{C}$ for $2 \mathrm{~h}$ provided the silylated product 6 in $89 \%$ NMR yield ( $88 \%$ isolated yield) (Entry 1). The yield of 6 was competitive (83\%) with the use of the catalyst generated in situ from $\mathrm{Pd}_{2} \mathrm{dba}_{3}$ and MePhos (Entry 2). An influence of ligands on the efficiency of the reaction was examined first. Monodentate ligands, $P C y_{3}$, CyJohnPhos, and JohnPhos afforded 6 in competitive yet lower yields (51-81\%) (Entry 3-5). 
Scheme 1. Synthesis of Sodium Silylsilanolates.

A. Synthesis of Sodium Trimethysilyldimethylsilanolate

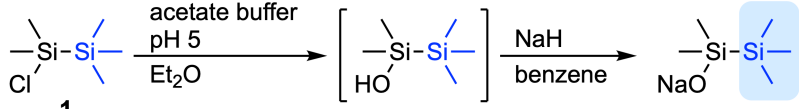

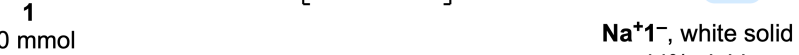

$$
\begin{aligned}
& 44 \% \text { yield }
\end{aligned}
$$

B. Synthesis of Sodium Dimethylalkylsilylsilanolate via Mono-substitution of 1,2-Dichlorotetramethyldisilane

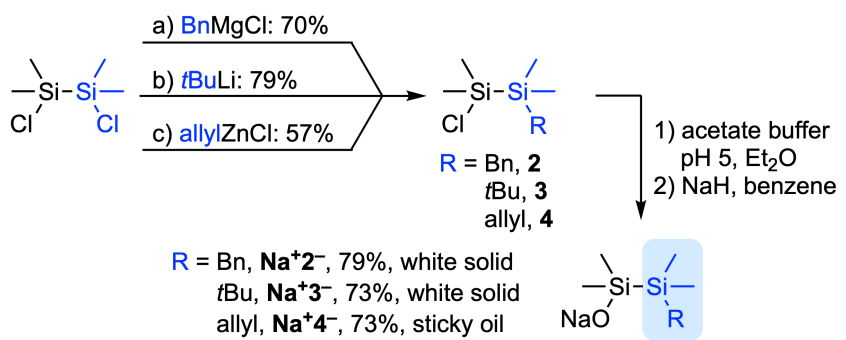

Scheme 1. Synthesis of Sodium Silylsilanolates. a) 1.05 equiv 1,2-dichlorotetramethyldisilane, 1.0 equiv $\mathrm{BnMgCl}$, THF, 0 to $50{ }^{\circ} \mathrm{C}, 4 \mathrm{~h}$. b) 1.03 equiv 1,2 -dichlorotetramethyldisilane, 1.0 equiv $t \mathrm{BuLi}$, hexane, reflux, 13 h. c) 1.0 equiv $1,2-$ dichlorotetramethyldisilane, 1.0 equiv allylZnCl, THF, $0{ }^{\circ} \mathrm{C}$ to r.t., $4 \mathrm{~h}$.

Table 1. Optimization of the Reaction Conditions.
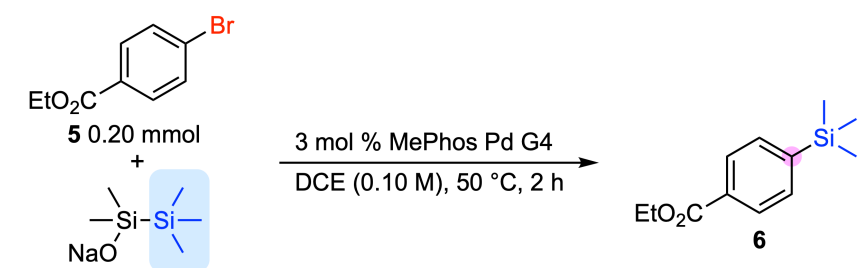

\begin{tabular}{|c|c|c|}
\hline Entry & Deviations from standard conditions & Yield $(\%)^{[a]}$ \\
\hline 1 & none & $89(88)^{[b]}$ \\
\hline 2 & $1.5 \mathrm{~mol} \% \mathrm{Pd}_{2} \mathrm{dba}_{3}+3 \mathrm{~mol} \%$ MePhos & 83 \\
\hline 3 & $1.5 \mathrm{~mol}_{0} \mathrm{Pd}_{2} \mathrm{dba}_{3}+3 \mathrm{~mol} \% \mathrm{PCy}_{3}$ & 80 \\
\hline 4 & $1.5 \mathrm{~mol} \% \mathrm{Pd}_{2} \mathrm{dba}_{3}+3 \mathrm{~mol} \%$ CyJohnPhos & 75 \\
\hline 5 & $1.5 \mathrm{~mol} \% \mathrm{Pd}_{2} \mathrm{dba}_{3}+3 \mathrm{~mol} \%$ JohnPhos & 51 \\
\hline 6 & $3 \mathrm{~mol} \%$ (IPr)Pd(allyl)Cl & 72 \\
\hline 7 & $1.5 \mathrm{~mol} \% \mathrm{Pd}_{2} \mathrm{dba}_{3}+3 \mathrm{~mol} \% \mathrm{dppe}$ & 7 \\
\hline 8 & $\mathbf{K}^{+} \mathbf{1}^{-}$ & 31 \\
\hline 9 & toluene & 74 \\
\hline 10 & THF & 25 \\
\hline 11 & $\mathrm{CH}_{3} \mathrm{CN}$ & 14 \\
\hline 12 & without MePhos Pd G4 & 0 \\
\hline
\end{tabular}

$\mathrm{Na}^{+} \mathbf{1}^{-} 2.0$ equiv

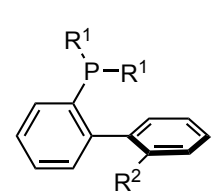

$\mathrm{R}^{1}=\mathrm{Cy}, \mathrm{R}^{2}=\mathrm{Me}:$ MePhos

$\mathrm{R}^{1}=\mathrm{Cy}, \mathrm{R}^{2}=\mathrm{H}$ : CyJohnPhos

$\mathrm{R}^{1}=t \mathrm{Bu}, \mathrm{R}^{2}=\mathrm{H}:$ JohnPhos
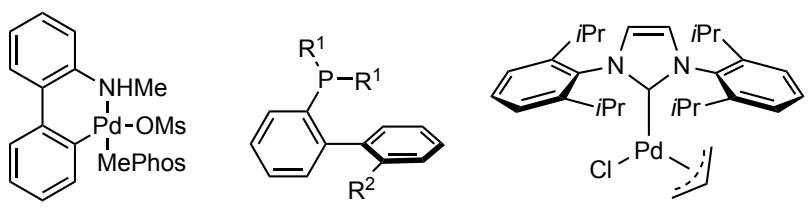

(IPr)Pd(allyl)Cl

MePhos Pd G4

[a] Yields were determined by ${ }^{1} \mathrm{H}$ NMR using 1,3,5-trimethoxybenzene as an internal standard. [b] Isolated yield (0.50 mmol scale). 
An acceptable result was also obtained with $N$-heterocyclic carbene complex (IPr)Pd(allyl)Cl as a catalyst (73\%) (Entry 6). A bidentate phosphine ligand, dppe, was ineffective (7\%) in the current reaction system (Entry 7). Use of potassium silylsilanolate, $\mathbf{K}^{\mathbf{+}} \mathbf{1}^{-}$, showed lower efficiency (Entry 8), which underscored the importance of the choice of the countercation for efficient silylation. The reaction in toluene was similarly efficient (74\%), while low yields were observed in $\mathrm{THF}$ and $\mathrm{CH}_{3} \mathrm{CN}$ with the recovery of most of the substrate (Entry 9-11) in concomitant with the formation of the reduced product $(<20 \%)$. No conversion of $\mathbf{5}$ was observed in the absence of a palladium catalyst (Entry 12).

Table 2. Scope of Silylation of Aryl Bromides.

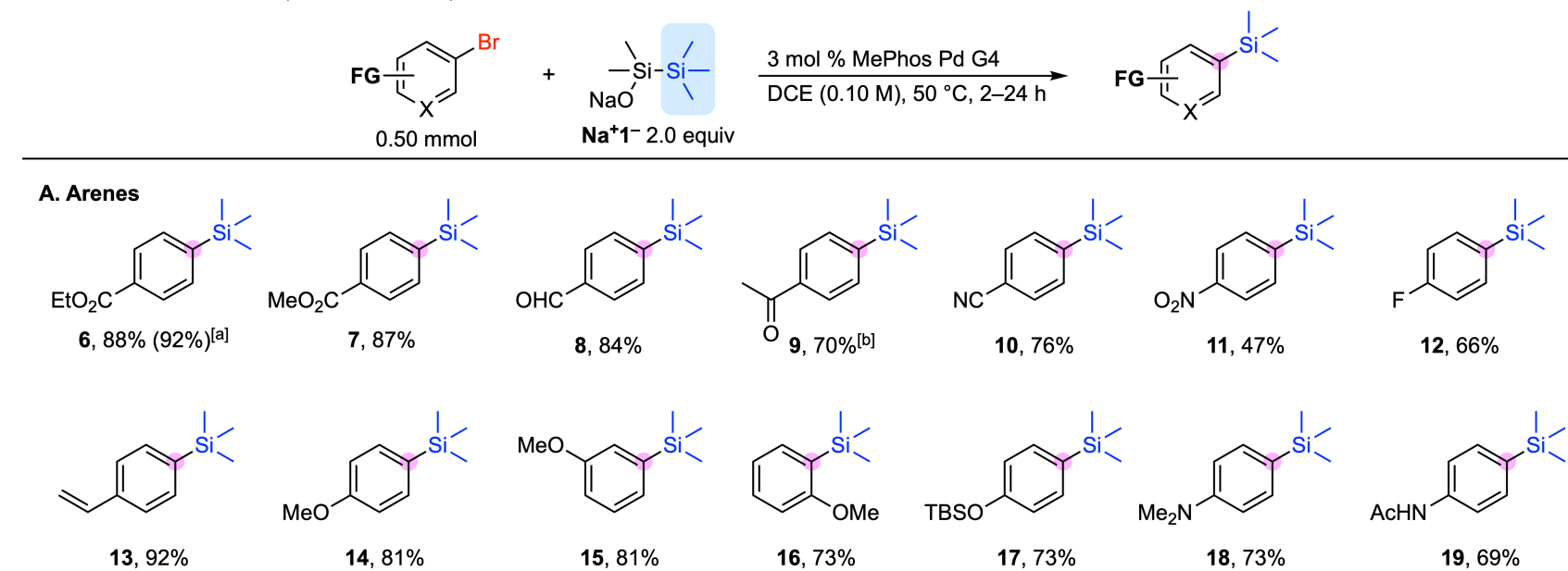

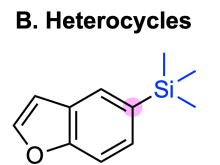

$20,98 \%$

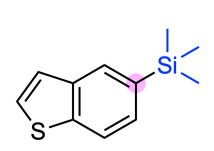

21, $93 \%$<smiles>Cn1ccc2cc([Si](C)(C)C)ccc21</smiles>

22, $97 \%$<smiles>Cn1ccc2cc([Si](C)(C)C)cnc21</smiles>

23, $100 \%$

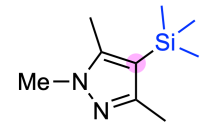

24, $53 \%$<smiles>C[Si](C)(C)c1cnc2ccccc2c1</smiles>

25, $85 \%$<smiles>C[Si](C)(C)c1ccc(N2CCOCC2)nc1</smiles>

26, $91 \%$<smiles>C[Si](C)(C)c1cnc(OC(=O)c2ccccc2)nc1</smiles>

$27,80 \%$<smiles>C[Si](C)(C)c1cnc(N2CCN(C(=O)OCc3ccccc3)CC2)nc1</smiles>

28, $92 \%$ (with $\left.\mathrm{Si}_{2} \mathrm{Me}_{6}: 31 \%\right)^{[c]}$

C. Bioactive Molecules Containing TMS Group

D. Drug-like Complex Molecules

Sulfadimethoxine analog
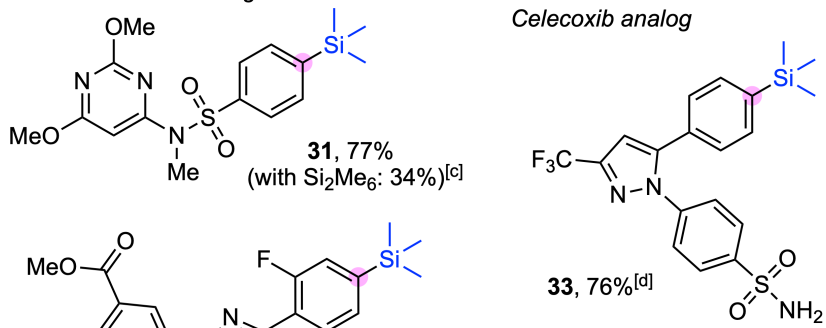

from SC-558

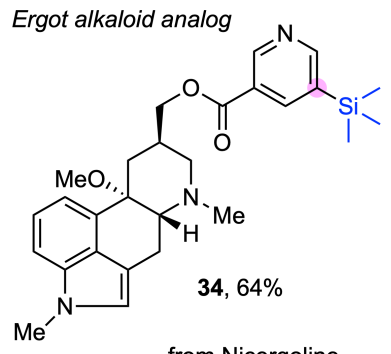

Fenazaquin analog

Ataluren analog

$32,53 \%[d]$

[a] $5.0 \mathrm{mmol}$ scale. [b] Temperature: $25^{\circ} \mathrm{C}$. [c] NMR yield. Reaction conditions: 1.2 equiv hexamethyldisilane, $1.5 \mathrm{~mol} \%$ $\mathrm{Pd}_{2} \mathrm{dba}_{3}, 9$ mol\% JohnPhos, 5.0 equiv KF, 2.0 equiv $\mathrm{H}_{2} \mathrm{O}$, DMPU $(0.90 \mathrm{~mL}), 100{ }^{\circ} \mathrm{C}, 12 \mathrm{~h}$. [d] $6 \mathrm{~mol} \% \mathrm{MePhos}$ Pd G4 and 3.0 equiv $\mathbf{N a}^{+} \mathbf{1}^{-}$were used. 
Next, we explored the reaction scope with respect to aryl bromides (Table 2). Silylation of $\mathbf{5}$ could be run even on a $5.0 \mathrm{mmol}$ scale to afford 6 in excellent yield (92\%). The reaction could tolerate various electronic and steric properties of substituents (6-11). Esters in $\mathbf{6}$ and $\mathbf{7}$ survived the silylation conditions. This outcome is intriguing given that trimethylsilanolates are generally used for the hydrolysis of esters. ${ }^{[14]}$ The substrate with formyl or acetyl group could be transformed in good yield to 8 or $\mathbf{9}$. In the case of $\mathbf{9}$, the reaction was performed at $25^{\circ} \mathrm{C}$ to suppress the formation of an a-arylated byproduct. Cyano and nitro groups could poison a palladium catalyst. While substrates with cyano group were converted into arylsilane $\mathbf{1 0}$ in good yield, arylsilane 11 with nitro group was obtained only in moderate yield. Fluoro and vinyl substituents were also confirmed to be compatible $(\mathbf{1 2}, \mathbf{1 3})$. Substrates with electron-rich substituents, such as methoxy $\left(p-, m_{-}, o^{-}\right.$ OMe), silyloxy, amino, and amido-substituted aryls were generally transformed to arylsilanes (1419). A wide range of heteroaryl trimethylsilanes could also be synthesized under our silylation reaction. Electron-rich heteroarenes such as benzofuran 20, benzothiophene 21, $N-(p-$ toluenesulfonyl)indole $\mathbf{2 2}$, and $\mathrm{N}$-methylpyrrolopyridine $\mathbf{2 3}$ were obtained in excellent yields. A sterically hindered pyrazole was converted to the silylated product $\mathbf{2 4}$ albeit in moderate yield (53\%). Electron-deficient heteroarenes were also compatible. The conditions were amenable to the syntheses of quinoline $\mathbf{2 5}$, as well as pyridine $\mathbf{2 6}$ and pyrimidines $\mathbf{2 7}, \mathbf{2 8}$. The reaction was also applicable to the synthesis of known biologically relevant compounds (Table 2C). Acetylcholinesterase inhibitor Zifrosilone ${ }^{[15]}$ (29) was synthesized from the commercially available 3'-bromo-2,2,2-trifluoromethylacetophenone in good yield. A potent inhibitor of the drugresistant S31N mutant of the M2 ion channel of influenza A virus $\mathbf{3 0}^{[16]}$ was synthesized from the corresponding aryl bromide even in the presence of a free hydroxy and a secondary amino group.

In an effort to demonstrate the applicability of our method to the late-stage silylation, we tested several drugs and drug-like molecules containing aryl bromides (Table 2D). Trimethylsilylated analogs of Sulfadimethoxine $\mathbf{3 1}$ and Ataluren $\mathbf{3 2}$ were synthesized in 77\% and 53\% respective yields from the corresponding aryl bromides. The bromide moiety of SC-558 was similarly converted to TMS group to give a Celecoxib analog 33 in $76 \%$ yield. Nicergoline was also trimethylsilylated to give an Ergot alkaloid analog 34 in $64 \%$ yield. An increased amount of the catalyst and silylsilanolate was required for Ataluren and Celecoxib analogs whose oxadiazole and sulfonamide moiety might work inhibitively to the catalyst. Thus, in the case of Ataluren analog, the slower rate of the coupling reaction seemed to result in partial hydrolysis of the ester moiety in 32. Sila-analog of Fenazaquin $35^{[17]}$ in which tert-butyl group is replaced with trimethylsilyl group, was analogously synthesized from the corresponding aryl bromide in excellent yield. Just to compare the functional group tolerance, the known palladium-catalyzed silylation conditions ${ }^{[\mathrm{fh}]}$ 
using hexamethyldisilane was applied for the syntheses of relatively functionalized $\mathbf{2 8}$ and $\mathbf{3 1}$, which resulted in $31 \%$ and $34 \%$ respective yields. The reaction proceeded in concomitant with the formation of the reduced products both in ca. 30\% yields with an about $30 \%$ recovery of the starting material (See SI). These results indicate that the new silylation strategy using sodium silylsilanolate is suitable for the highly versatile syntheses of sila-analogs of bioactive molecules.

We applied the optimized silylation conditions to other aryl halides and pseudohalides (Table 3). For electron-deficient arenes, iodide, triflate, and chloride were silylated to provide $\mathbf{6}$ in high yields. lodide could be transformed even at $25{ }^{\circ} \mathrm{C}$. For an electron-rich series, aryl iodide was also converted to the corresponding product 14 in high yield while triflate and chloride showed low or no conversion even under the optimized conditions. Silylation of aryl triflate and chloride on more functionalized molecules was also achieved. The silylated products 36, 37 were obtained from estrone derivative $(X=\mathrm{OTf})$ or fenofibrate $(\mathrm{X}=\mathrm{Cl})$ respectively in high yields. In the case of a protected L-tyrosine derivative $(\mathrm{X}=\mathrm{OTf})$, the silylated product $\mathbf{3 8}$ was obtained in good yield albeit in an almost racemized form.

Table 3. Scope of Silylation of Aryl Halides and Pseudohalides.

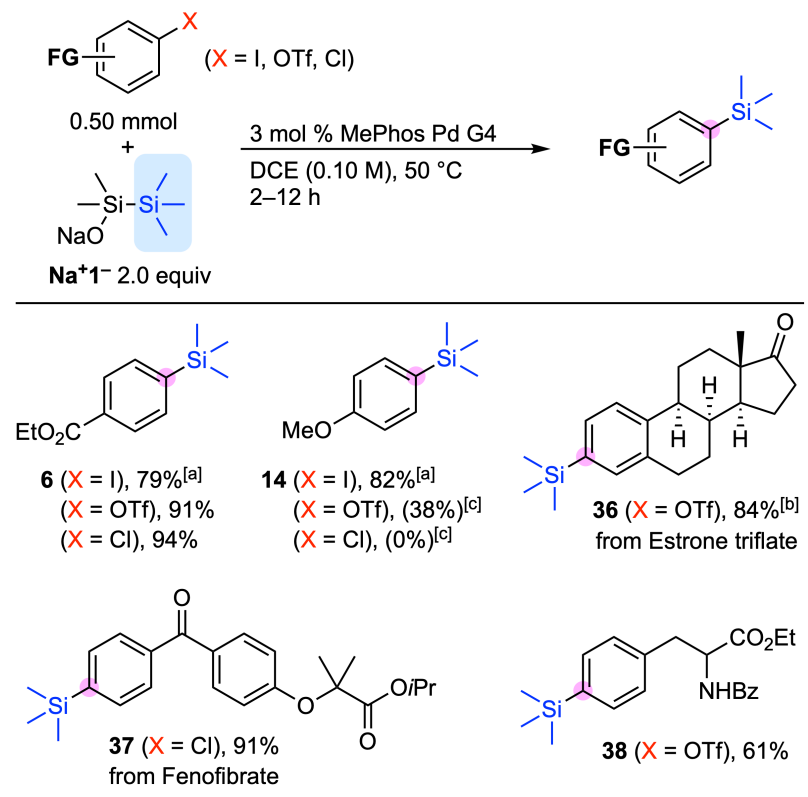

[a] Temperature: $25^{\circ} \mathrm{C}$. [b] 6 mol \% MePhos Pd G4 was used. [c] NMR yield.
Table 4. Scope of Silyl Groups.

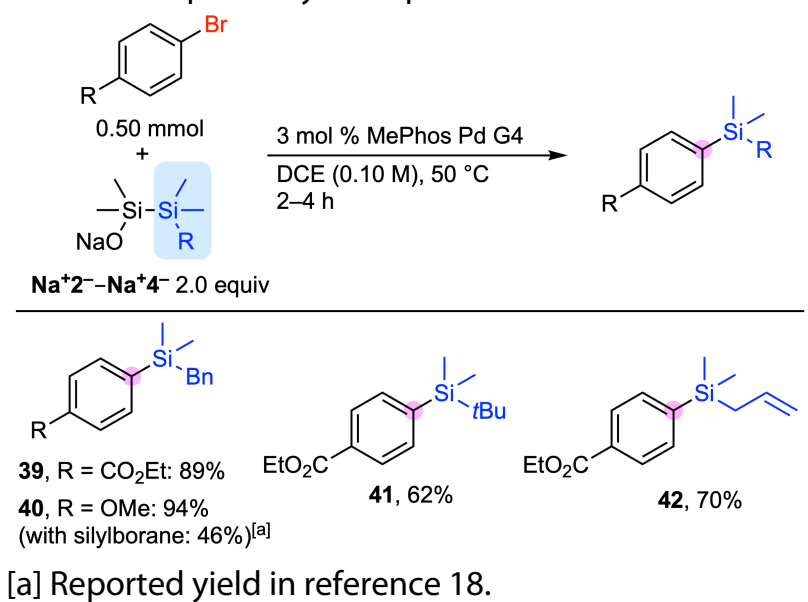

With $\mathrm{Na}^{+} \mathbf{2}^{-}-\mathrm{Na}^{+} 4^{-}$, introduction of other silyl groups was also possible in the current strategy (Table 4). Delivery of benzyldimethylsilyl group has been known to be inefficient with a disilane ${ }^{[6 \mathrm{~m}]}$ or silylborane ${ }^{[18]}$ as a precursor. Under the optimized conditions with $\mathrm{Na}^{+} \mathbf{2}^{-}$, benzyldimethylsilyl group could be introduced to afford both electron-deficient and donating arenes $\mathbf{3 9}$ and $\mathbf{4 0}$ in 
high yields. In the case of $p$-bromoanisole, the yield of $\mathbf{4 0}$ under the current conditions (94\%) is higher than the one in the known result with silylborane-based conditions. ${ }^{[18]}$ While no coupling reaction with tert-butyldimethylsilyl (TBDMS) group and allyldimethylsilyl group has so far been reported under transition metal-catalyzed conditions with conventional silylating reagents, our silylation method with silylsilanolates $\mathrm{Na}^{+} 3^{-}$and $\mathbf{N a}^{+} 4^{-}$enabled an easy access to the TBDMS arene $41(62 \%)$ and allylsilylated arene 42 (70\%). These results indicate that the core structure of silylsilanolate would be generally more viable for the transmetalation of various silyl groups than the known silylating reagents.

To gain mechanistic insights into the silylation with silylsilanolates, we conducted ${ }^{31} \mathrm{P}$ and ${ }^{19} \mathrm{~F}$ NMR experiments (Figure 3 and S1). T-shape complex SPhosPdBr(4-FC $\left.\mathrm{H}_{6} \mathrm{H}_{4}\right)$ (43) was synthesized from 4- $\mathrm{FC}_{6} \mathrm{H}_{4} \mathrm{Br}$, $\mathrm{Pd}(\mathrm{cod})\left(\mathrm{CH}_{2} \mathrm{SiMe}_{3}\right)_{2}$, and SPhos. ${ }^{[19]}$ As reported by Hii, Pd complexes with SPhos such as $\mathbf{4 3}$ were known to show two signals corresponding to the monomer of $\mathbf{4 3}$ and its $\mu_{2}$-halobridged dimer (Figure 3A) ${ }^{[20]}$ Cationic Pd (II) species $\mathbf{4 4}$ was prepared in situ by the reaction of $\mathbf{4 3}$ with $\mathrm{NaBAr}_{4}$ at $0{ }^{\circ} \mathrm{C}\left(\mathrm{Ar}^{\mathrm{F}}=3,5-\left(\mathrm{CF}_{3}\right)_{2} \mathrm{C}_{6} \mathrm{H}_{3}\right){ }^{[21]}$ which showed a downfield shift of ${ }^{31} \mathrm{P}$ NMR signal ${ }^{[22]}$ at 49.4 ppm (Figure 3B). Upon treatment of 44 with 0.5 equiv of $\mathbf{N a}^{+} \mathbf{1}^{-}$at $-30{ }^{\circ} \mathrm{C}$, a new ${ }^{31} \mathrm{P} \mathrm{NMR}$ signal appeared (37.8 ppm), in addition to the broadened signal for the remaining 44 (Figure 3C). After the addition of an additional 0.5 equiv of $\mathbf{N a}^{+} \mathbf{1}^{-}$to the solution at $-30^{\circ} \mathrm{C}, 44$ was fully consumed, leaving the species that shows the sharp signal at 38.0 ppm with a broadened signal at $41.2 \mathrm{ppm}$ (Figure 3D). The stoichiometry obtained in these experiments revealed that the attack of $\mathrm{Na}^{+} \mathbf{1}^{-}$to 44 rapidly occurred and resulted in the formation of a $\mathrm{Pd}$ species 45 bearing a silylsilanolate substituent. ${ }^{[19]}$ We attributed the slight shift of the broadened signal of $\mathbf{4 4}$ in Figure $3 \mathrm{C}$ to the fast equilibrium between the free cationic 44 and a complex of 44 and $\mathbf{4 5}$. By analogy to Figure $3 A$, the sharp signal at $38.0 \mathrm{ppm}$ and the broad peak at $41.2 \mathrm{ppm}$ in Figure 3D could be respectively assigned as the monomeric species of $\mathbf{4 5}$ and its silanolate-bridged dimer. ${ }^{19} \mathrm{~F}$ NMR study was separately conducted for the same time courses (See SI). The product that formed in the reaction was confirmed to be the coupled product 4-fluorotrimethylsilylbenzene from the ${ }^{19} \mathrm{~F}$ NMR spectrum. Also, after the solution of $\mathbf{4 5}$ was warmed to room temperature, the ${ }^{19} \mathrm{~F}$ NMR signal showed the disappearance of $\mathbf{4 5}$. These NMR experiments corroborated the hypothesis that silylsilanolate-coordinated species $\mathbf{4 5}$ was a viable intermediate for the palladium-catalyzed silylation. 


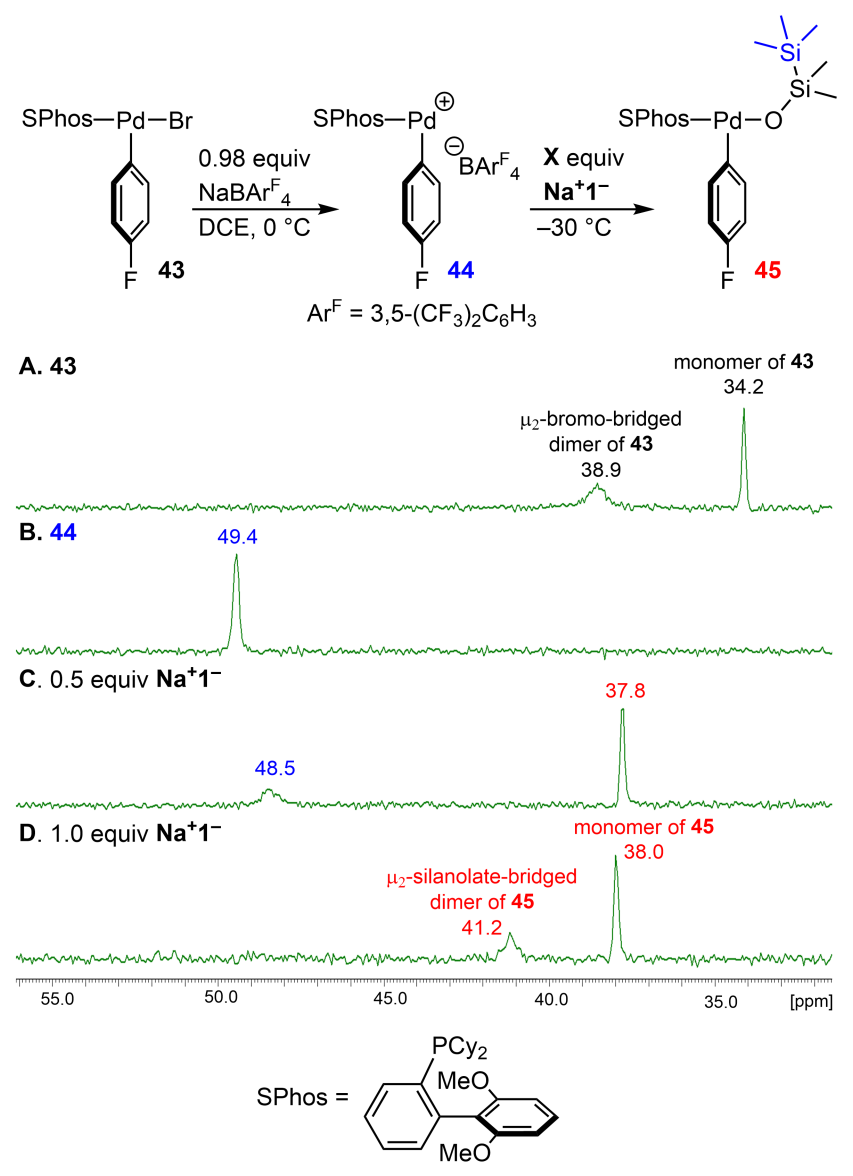

Figure 3. Sequential ${ }^{31}$ P NMR Spectra on the Ligand Exchange of $\mathbf{4 3}$ with Sodium Silylsilanolate.

To figure out the mechanism of the migration of the silyl groups to palladium atom of 45, DFT calculations were carried out (Figure 4). Based on the results of the ${ }^{31} \mathrm{P}$ NMR experiments, silylsilanolate-coordinated arylpalladium INT-1 was chosen as a reliable starting point of the calculated pathway. To simplify the calculations, the ligand was modeled as 2(diisopropylphosphino)biphenyl. A pathway for the migration of the silyl group directly from INT1 (non-assisted pathway) was initially examined. The energy profile is summarized on the left side of Figure 4. The pathway for the direct elimination of dimethylsilanone (46) from INT-1 to afford INT-A2 via TS-A and INT-A1 was found to be endergonic probably because of the thermodynamically unfavorable generation of a silanone. As the calculated activation energy from INT-1 to TS-A is $34.8 \mathrm{kcal} / \mathrm{mol}$, direct transfer of the silyl group to give $\mathbf{4 7}$ is not a likely pathway. We next hypothesized that sodium silylsilanolates that exist in large excess compared with the palladium species would promote the migration of a silyl group. Experimental observations revealed that non-polar solvents such as DCE and toluene were effective for the silylation, so we assumed that an aggregated cluster of sodium silylsilanolates may have an effect on the migration process. To simplify the calculation, an activator was modeled as sodium trimethylsilanolate dimer 48. The energy profile with the aid of $\mathbf{4 8}$ is summarized on the right side of Figure 4 (silanolate dimer-assisted pathway). The complexation of INT-1 with the sodium trimethylsilanolate dimer $\mathbf{4 8}$ 


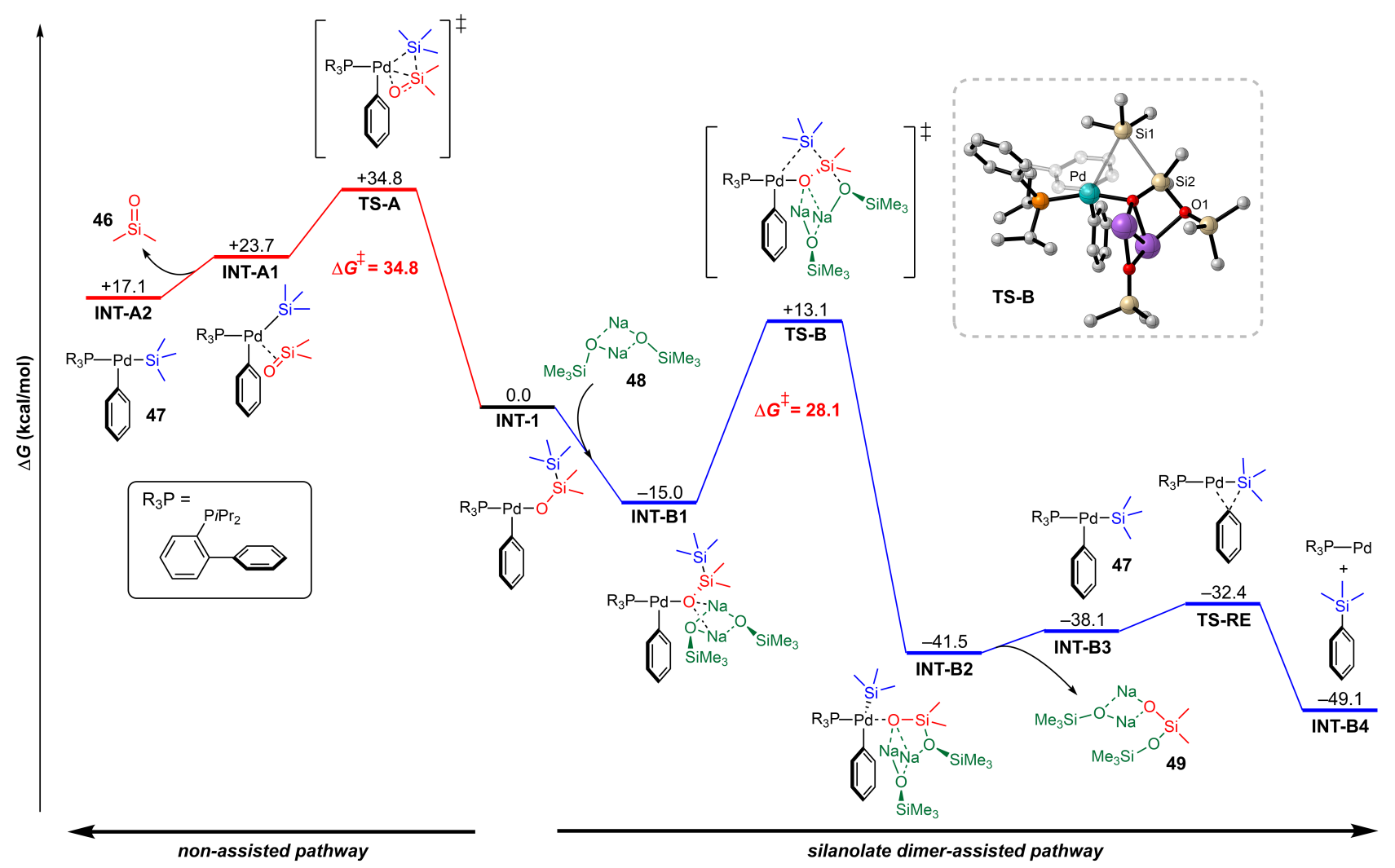

Figure 4. Energy Profile for Migration of Silyl Group of Silylsilanolate to Palladium Atom at the $\omega B 97 X-D / d e f 2-$

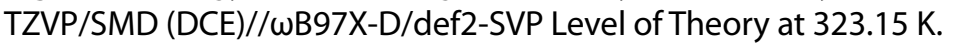

proceeds exergonically to afford INT-B1. The intramolecular transfer of the trimethylsilyl group to the palladium atom requires a lower activation barrier $\left(\Delta G^{\ddagger}=28.1 \mathrm{kcal} / \mathrm{mol}\right)$ via TS-B to afford INTB2 than that via TS-A. In the calculated structure of TS-B shown in Figure 4, the silicate moiety on Si2 atom forms a trigonal bipyramidal structure where Si1 and $\mathrm{O} 1$ atoms occupy the apical positions. NBO analysis revealed that the NPA charge of the trimethylsilyl unit of the silylsilanolate in TS-B (-0.552 e) was significantly more negative than the one in TS-A1 (-0.110 e) (See SI). In addition, each of NPA charges of Si1 and Si2 atoms in TS-B is +0.875 e and +2.081 e, which indicates Si1 atom is more negatively charged. Thus, through the formation of silicate-like structure in TS-B, the trimethylsilyl unit containing Si1 atom is rendered anionic to result in the smooth combination of the Si1 unit with the nearby palladium atom. Dissociation of a silanolate bearing disiloxane moiety 49 from INT-B2 affords INT-B3. Cluster 49 that goes off in the course of the reaction would again assist in the activation of the transfer of the silyl group. Of note, our simplified calculation model based on a sodium silanolate dimer does not exclude the possibility of the interference of a larger cluster of silanolates. From these results, we conclude that the transfer of the silyl group proceeds with the aid of a cluster of silanolates that would exist in the reaction mixture. ${ }^{[23]} \mathrm{A}$ calculation on the reductive elimination of $\mathbf{4 7}$ indicates that the final reductive elimination is a lowbarrier process through TS-RE $\left(\Delta G^{\ddagger}=5.7 \mathrm{kcal} / \mathrm{mol}\right)$ to exergonically afford INT-B4. This result is 
consistent with the fact that such silylpalladium species was not observed either in the ${ }^{31} \mathrm{P}$ or ${ }^{19} \mathrm{~F}$ NMR experiments.

\section{Conclusion}

We have developed a new class of practical silylating reagent, sodium silylsilanolates, and confirmed their efficiency for the delivery of silyl groups in the palladium-catalyzed silylation of aryl (pseudo)halides. The new silylation method with silylsilanolates allowed an introduction of a series of silyl groups including the ones that have been regarded to be laborious. A good functional group tolerance exhibited under the conditions proved an applicability to the late-stage silylation of drugs and complex molecules. Mechanistic studies with ${ }^{31} \mathrm{P}$ and ${ }^{19} \mathrm{~F}$ NMR experiments and DFT calculations revealed a plausible reaction mechanism for the intramolecular transfer of the terminal silyl group on a silanolate to palladium center, which was assisted by a cluster of silanolates. These results unveiled a broader potential versatility of sodium silylsilanolates as reagents for transferring a broad silyl groups in a range of challenging silylating transformations. Development of other silylsilanolate species and further applications of alkali metal silylsilanolates in combination with other transition metal catalysts will be reported in due course.

\section{Acknowledgements}

This work was supported by JSPS KAKENHI Grant Numbers JP21H01934, JP20J23393, JP19H00895, JP18J22838 and partly by JST CREST Grant Number JPMJCR19R4, Japan. H. Yamagishi acknowledges a JSPS Predoctoral Fellowship. J.S. thanks the support by The Sumitomo Foundation.

[1] For reviews about silicon-containing drugs, see: a) R. Tacke, S. Dörrich, in Atypical Elements in Drug Design (Ed.: J. Schwarz) 2016, pp. 29-59; b) G. A. Showell, J. S. Mills, Drug Discov. 2003, 8, 551-556; c) S. McN. Sieburth, C.-A. Chen, Eur. J. Org. Chem. 2006, 311-322; d) N. A. Meanwell, J. Med. Chem. 2011, 54, 2529-2591; e) A. K. Franz, S. O. Wilson, J. Med. Chem. 2013, 56, 388-405; f) S. Fujii, Y. Hashimoto, Future Med. Chem. 2017, 9, 485-505; g) R. Ramesh, D. S. Reddy, J. Med. Chem. 2018, 61, 3779-3798.

[2] a) J. O. Daiss, C. Burschka, J. S. Mills, J. G. Montana, G. A. Showell, I. Fleming, C. Gaudon, D. Ivanova, H. Gronemeyer, R. Tacke, Organometallics 2005, 24, 3192-3199; b) J. B. Bauer, W. P. Lippert, S. Dörrich, D. Tebbe, C. Burschka, V. B. Christie, D. M. Tams, A. P. Henderson, B. A. Murray, T. B. Marder, S. A. Przyborski; R. Tacke, ChemMedChem 2011, 6, 1509-1517.

[3] C. Zhou, J. Cheng, R. Beadle, F. G. Earley, Z. Li, P. Maienfisch, Bioorg. Med. Chem. 2020, 28, 115509.

[4] M. J. Barnes, R. Conroy, D. J. Miller, J. S. Mills, J. G. Montana, P. K. Pooni, G. A. Showell, L. M. Walsh, J. B. H. Warneck, Bioorg. Med. Chem. Lett. 2007, 17, 354-357.

[5] a) M. Murata, K. Suzuki, S. Watanabe, Y. Masuda, J. Org. Chem. 1997, 62, 8569-8571; b) A. S. Manoso, P. J. DeShong, Org. Chem. 2001, 66, 7449-7455; c) Y. Yamanoi, J. Org. Chem. 2005, 70, 9607-9609; For a review, see: d) Z. Xu, W.S. Huang, J. Zhang, L.-W. Xu, Synthesis 2015, 47, 3645-3668. 
[6] a) H. Matsumoto, S. Nagashima, K. Yoshihiro, Y. Nagai, J. Organomet. Chem. 1975, 85, C1-C3; b) D. Azarian, S. S. Dua, C. Eaborn, D. R. M. Walton, J. Organomet. Chem. 1976, 117, C55-C57; c) C. Eaborn, R. W. Griffiths, A. Pidcock, J. Organomet. Chem. 1982, 225, 331-341; d) Y. Hatanaka, T. Hiyama, Tetrahedron Lett. 1987, 28, 4715-4718; e) P. Babin, B. Bennetau, M. Theurig, J. Dunoguès, J. Organomet. Chem. 1993, 446, 135-138; f) Y. Ishii, N. Chatani, S. Yorimitsu, S. Murai, Chem. Lett. 1998, 27, 157-158; g) E. Shirakawa, T. Kurahashi, H. Yoshida, T. Hiyama, Chem. Commun. 2000, 1895-1896; h) L. J. Gooßen, A.-R. S. Ferwanah, Synlett 2000, 1801-1803; i) S. E. Denmark, J. M. Kallemeyn, Org. Lett. 2003, 5, 3483-3486; j) T. Iwasawa, T. Komano, A. Tajima, M. Tokunaga, Y. Obora, T. Fujihara, Y. Tsuji, Organometallics 2006, 25, 4665-4669; k) M. Tobisu, Y. Kita, N. Chatani, J. Am. Chem. Soc. 2006, 128, 81528153; I) E. McNeill, T. E. Barder, S. L. Buchwald, Org. Lett. 2007, 9, 3785-3788; m) M. Tobisu, Y. Kita, Y. Ano, N. Chatani, J. Am. Chem. Soc. 2008, 130, 15982-15989; n) Y. Yamamoto, H. Matsubara, K. Murakami, H. Yorimitsu, A. Osuka, Chem. Asian J. 2015, 10, 219-224; o) K. Fukui, H. Saito, J. Shimokawa, H. Yorimitsu, Synlett 2020, 31, $1328-1332$.

[7] For reviews on silylboranes, see: a) M. Oestreich, E. Hartmann, M. Mewald, Chem. Rev. 2013, 113, 402-441; b) J.-J. Feng, W. Mao, L. Zhang, M. Oestreich, Chem. Soc. Rev. 2021, 50, 2010-2073.

[8] a) J. Zhang, Y. Zhang, S. Geng, S. Chen, Z. Liu, X. Zeng, Y. He, Z. Feng, Org. Lett. 2020, 22, 2669-2674; b) Y. Wu, Y.H. Huang, X.-Y. Chen, P. Wang, Org. Lett. 2020, 22, 6657-6661.

[9] E. Yamamoto, R. Shishido, T. Seki, H. Ito, Organometallics 2017, 36, 3019-3022.

[10] T. Kurahashi, T. Hata, H. Masai, H. Kitagawa, M. Shimizu, T. Hiyama, Tetrahedron 2002, 58, 6381-6395.

[11] a) K. Hirabayashi, J. Kawashima, Y. Nishihara, A. Mori, T. Hiyama, Org. Lett. 1999, 1, 299-301; b) S. E. Denmark, R. F. Sweis, J. Am. Chem. Soc. 2001, 123, 6349-6440; c) K. Hirabayashi, A. Mori, J. Kawashima, M. Suguro, Y. Nishihara, T. Hiyama, J. Org. Chem. 2000, 65, 5342-5349; d) S. E. Denmark, R. F. Sweis, Acc. Chem. Res. 2002, 35, 835-846; e) S. E. Denmark, R. C. Smith, W.-T. T. Chang, J. M. Muhuhi, J. Am. Chem. Soc. 2009, 131, 3104-3118; f) S. E. Denmark, R. C. Smith, J. Am. Chem. Soc. 2010, 132, 1243-1245; g) S. A. Tymonko, R. C. Smith, A. Ambrosi, M. H. Ober, H. Wang, S. E. Denmark, J. Am. Chem. Soc. 2015, 137, 6200-6218.

[12] In the case of $\mathbf{4}$, the use of preformed allylic zinc reagent showed a better reproducibility than in the Sakurai's seminal work. T. Sanji, M. Iwata, M. Watanabe, T. Hoshi, H. Sakurai, Organometallics 1998, 17, 5068-5071.

[13] The new precatalyst, MePhos Pd G4, was synthesized according to the reported procedure: N. C. Bruno, N. Niljianskul, S. L. Buchwald, J. Org. Chem. 2014, 79, 4161-4166. The detail of the synthesis is described in SI.

[14] a) E. D. Laganis, B. L. Chenard, Tetrahedron Lett. 1984, 25, 5831-5834; b) M. Lovrić, I. Cepanec, M. Litvić, A. Bartolinčić, V. Vinković, Croat. Chim. Acta 2007, 80, 109-115.

[15] a) J.-M. Hornsperger, J.-N. Collard, J.-G. Heydt, E. Giacobini, S. Funes, J. Dow, D. Schirlin, Biochem. Soc. Trans. 1994, 22, 758-763; b) N. R. Cutler, R. D. Seifert, M. M. Schleman, J. J. Sramek, O. J. Szylleyko, D. R. Howard, A. Barchowsky, T. S. Wardle, E. P. Brass, Clin. Pharmacol. Ther. 1995, 58, 54-61; c) X. D. Zhu, E. Giacobini, J.-M. Hornsperger, Eur. J. Pharmacol. 1995, 276, 93-99.

[16] Y. Hu, Y. Wang, F. Li, C. Ma, J. Wang, Eur. J. Med. Chem. 2017, 135, 70-76.

[17] B. A. Dreikorn, R. G. Suhr, G. P. Jourdan, I. G. Wright, Eur. Pat. Appl. 0326329A2, 1989.

[18] R. Shishido, M. Uesugi, R. Takahashi, T. Mita, T. Ishiyama, K. Kubota, H. Ito, J. Am. Chem. Soc. 2020, 142, $14125-14133$.

[19] J. J. Molloy, C. P. Seath, M. J. West, C. McLaughlin, N. J. Fazakerley, A. R. Kennedy, D. J. Nelson, A. J. B. Watson, J. Am. Chem. Soc. 2018, 140, 126-130.

[20] J. B. Brazier, M. A. Newton, E. M. Barreiro, L. A. Adrio, L. Naya, K. K. Hii, Dalton Trans. 2017, 46, 7223-7231.

[21] G. M. Borrajo-Calleja, V. Bizet, C. Besnard, C. Mazet, Organometallics 2017, 36, 3553-3563. 
[22] a) K. Shimomaki, K. Murata, R. Martin, N. Iwasawa, J. Am. Chem. Soc. 2017, 139, 9467-9470; b) R. McGarry, M. McDaniel, B. C. Chan, A. R. O'Connor, Polyhedron 2016, 114, 101-109.

[23] We also calculated the pathway of the migration of a silyl group with the aid of trimethylsilanolate monomer. This result indicates that in the silanolate monomer-assisted pathway, the activation barrier of cleavage of the Si-Si bond of silylsilanoalte is higher than the one in the non-assisted pathway. Details of the calculation result are shown in SI. 